\title{
Natural history of progressive supranuclear palsy (Steele-Richardson-Olszewski syndrome) and clinical predictors of survival: a clinicopathological study
}

I Litvan, C A Mangone, A McKee, M Verny, A Parsa, K Jellinger, L D'Olhaberriague, K Ray Chaudhuri, R K B Pearce

\begin{abstract}
Objective-To analyse the natural history of progressive supranuclear palsy (PSP or Steele-Richardson-Olszewski syndrome) and clinical predictors of survival in 24 patients with PSP confirmed by necropsy, who fulfilled the NINDS criteria for a neuropathological diagnosis of typical PSP.
\end{abstract}

Methods-Patients were selected from the research and clinical files of seven medical centres involving tertiary centres of Austria, England, France, and the United States. Clinical features were analysed in detail. The patients' mean age at onset of PSP was 63 (range 45-73) years.

Neuroepidemiology Branch, National Institute of

Neurological Disorders and Stroke, National Institutes of Health Bethesda, Maryland, USA

I Litvan

C A Mangone

L D'Olhaberriague

A Parsa

Department of

Neuropathology,

Massachusetts General

Hospital, Boston

Massachusetts, USA

A McKee

Raymond Escourolle

Neuropathology

Laboratory, Inserm U

360, Hôpital de la

Salpètrière, Paris,

France

M Verny

Ludwig Boltzmann

Institute of Clinical

Neurobiology, Vienna,

Austria

K Jellinger

Department of

Neurology, Institute of

Psychiatry, London,

UK

K Ray Chaudhuri

Parkinson's Disease

Society Brain Tissue

Bank, Institute of

Neurology, London,

UK

R K B Pearce

Correspondence to:

Dr Irene Litvan, Federal

Building, Room 714,

National Institute of

Neurological Disorders and

Stroke, National Institutes of

Health, Bethesda, Maryland

20892, USA.

Received 23 November 1995

and in revised form

5 February 1996

Accepted 8 February 1996
Results-The most frequent clinical features (occurring in at least $75 \%$ of the patients) were early postural instability and falls, vertical supranuclear palsy, akinetic-rigid predominant parkinsonian disorder characterised by symmetric bradykinesia and axial rigidity unrelieved by levodopa, pseudobulbar palsy, and frontal release signs. Occasionally, segmental dystonia or myoclonus were described, but neither aphasia nor alien limb syndrome was reported. Fractures occurred in $25 \%$ of the patients but were unrelated to the severity of the gait or to the presence of falls. Median survival time was 5.6 (range 2-16.6) years. Onset of falls during the first year, early dysphagia, and incontinence predicted a shorter survival time. Age at onset, sex, early onset of dementia, vertical supranuclear palsy, or axial rigidity had no effect on prognosis of survival. Pneumonia was the most common immediate cause of death. PSP was most often clinically misdiagnosed as Parkinson's disease. Errors in diagnosis suggest that PSP is underdiagnosed.

Conclusion-Progressive onset of early postural instability with falls or supranuclear vertical palsy in the fifth decade, should suggest the diagnosis of PSP. Onset of falls during the first year are emphasised, as they could lead to an early diagnosis and influence the prognosis of patients with PSP. Whether appropriate treatment of the dysphagia could prolong the survival of PSP patients needs to be explored.

$(\mathcal{F}$ Neurol Neurosurg Psychiatry 1996;61:615-620)
Keywords: progressive supranuclear palsy; natural history; survival

Progressive supranuclear palsy (PSP or SteeleRichardson-Olszewski syndrome) causes postural instability, supranuclear vertical ophthalmoplegia, parkinsonism unresponsive to levodopa, pseudobulbar palsy, and mild dementia. ${ }^{12}$ However, patients with PSP without ophthalmoplegia or dementia, or presenting only with dementia or akinesia, have also been reported. ${ }^{3-7}$

In the absence of laboratory markers for the diagnosis of PSP, neuropathological examination remains the "gold standard" for its diagnosis. Neuropathologically confirmed cases of corticobasal degeneration, multiple system atrophy, diffuse Lewy body disease, cerebrovascular disease, subcortical gliosis, and prion disease have been clinically misdiagnosed as PSP..$^{8-14}$ Thus PSP can be difficult to diagnose because of its increasingly recognised clinical diversity and because the topographic distribution of lesions in the basal ganglia and brainstem overlaps with what is found in other parkinsonian syndromes. ${ }^{15}{ }^{16}$ Moreover, PSP may be associated with more than one neuropathological diagnosis, such as Alzheimer's or Parkinson's disease. ${ }^{17}$

To develop a clinically useful description of the natural history of PSP which could improve the accuracy of its early diagnosis, ${ }^{16}$ we reviewed the records of the first and last visits of 24 patients with neuropathologically typical PSP confirmed at necropsy, ${ }^{18}$ and compared our findings with those of other confirmed series. ${ }^{15}{ }^{19-22} \mathrm{We}$ also evaluated the cause of death and clinical predictors of survival in these patients because both may provide useful insights into the management of patients with PSP.

\section{Methods}

Patients were selected from the research and clinical neuropathological files of seven medical centres of four countries (Austria, England, France, and the United States) by neuropathologists who based their selection on the recently published National Institute of Neurological Disorders and Stroke (NINDS) neuropathological criteria for the diagnosis of PSP..$^{18}$ Only neuropathologically typical cases of PSP, which were shown to have substantial reliability, ${ }^{23}$ were included in the study. Briefly, neuropathologically typical PSP 
includes a high density of neurofibrillary tangles and neuropil threads in at least three of the following areas: pallidum, subthalamic nucleus, substantia nigra, and pons, and a low to high density of neurofibrillary tangles or neuropil threads in at least three of the following areas: striatum, oculomotor complex, medulla, and dentate nucleus. It also requires the exclusion of other disorders including large or numerous infarcts; profound diffuse or focal atrophy; Lewy bodies; changes diagnostic of Alzheimer's disease; oligodendroglial argyrophilic inclusions; Pick bodies; diffuse spongiosis; or prion $\mathrm{P}$ positive amyloid plaques. All cases met the criteria for inclusion in the study - that is, neuropathological diagnosis of PSP made with at least a $75 \%$ degree of certainty by the neuropathologists who provided the cases, and detailed neurological examinations, including neurooculomotor examination, on the first and last visits.

The patients' records were abstracted on standardised forms by eight of us (AM, MV, KJ, KRC, RKBP, LD, IL, or CAM), who followed strict instructions. Signs or symptoms were recorded as missing data if they were not mentioned in the records. However, as the data were retrospectively collected, we assumed that neurologists performed complete examinations and considered that a feature (for example, supranuclear palsy) was absent when they reported that the examination was "within normal limits" (for example, cranial nerves). For the purpose of this study, upward gaze limitation was considered abnormal when either a restriction, in pursuit, or voluntary gaze, or both, of at least $50 \%$ of the normal range was described, or the upward supranuclear palsy was rated as moderate to severe. The severity of gait disturbance was classified as follows: $0=$ not affected; $1=\min$ imal (impaired but no assistance is needed); 2 $=$ mild (needs the use of a stick or walker); $3=$ moderate (needs the assistance of one or more persons); and $4=$ severe (unable to walk even with assistance).

Survival was calculated by the KaplanMeier and proportional hazards (Cox) life table analysis. ${ }^{24}$ Analysis of variance (ANOVA), the $\chi^{2}$ test, and the Spearman $r$ test were used for statistical analysis, as appropriate. ${ }^{24}$ Results are expressed as mean (SD); statistical significance was defined as $P \leqslant 0.05$.

\section{Results}

DEMOGRAPHIC

Table 1 shows the main demographic characteristics of the 24 patients. There were nine women and 15 men, a typical sex distribution for patients with PSP. The mean age at onset of PSP was 63 (SD 7) years; mean age at the first visit was 66.4 (SD 7) years; and mean age at death was 69.6 (SD 6.6) years. None of the patients had a familial parkinsonian disorder. Of the 24 patients, 21 were right handed, one was left-handed, one was ambidextrous, and one had no record of handedness.

\section{INITIAL SYMPTOMS OF PSP}

The onset of PSP symptoms was insidious and disease progression was steady. The initial symptom was most often $(63 \%, n=15)$ postural instability. Both postural instability and falls occurred during the first year in $58 \%$ of the patients. Dysarthria was the second most common symptom $(33 \%, \mathrm{n}=8)$, followed by bradykinesia $(13 \%, n=3)$. Visual disturbances (diplopia, blurred vision, burning eyes, light sensitivity) were the first symptoms in $13 \%(n=3)$ of the patients. Cognitive or behavioural changes generally followed these initial symptoms, but were the first symptoms in $8 \%(n=2)$ of the patients.

\section{SYMPTOMS AT FIRST VISIT}

The first clinical visit occurred a mean of $3 \cdot 7$ years (range 1-11 years) after onset of disease. At the first visit, most of the patients with PSP had gait disorder and postural instability, a history of falls, bilateral bradykinesia, a predominant akinetic-rigid course, axial rigidity, vertical supranuclear palsy, and dysarthria (table 2). Gait was unstable $(n=23)$, small stepped $(n=12)$, or broad based $(n=5)$. Falls were backwards in eight of 11 patients for whom the direction of the falls was described.

Supranuclear gaze deficits involved initially either downward or upward gaze and, later, horizontal gaze. The patients rarely presented with vertical supranuclear palsy at onset; it usually occurred three years after onset of disease, and in three patients it never developed. Moderate to severe upward gaze palsy was more frequent than downward gaze abnormalities ( $\mathrm{n}=19 v \mathrm{n}=16)$. Pursuit and voluntary saccades were affected early in the course of the disease, and often patients had abnormalities in convergence (although such data were often missing).

Speech was slurred $(n=15)$, dysphonic $(n=12)$, slow $(n=9)$, palilalic $(n=2)$, ataxic $(n=1)$, or unintelligible $(n=1)$. Frontal lobe type symptomatology (mainly decreased fluency, concrete thought, and difficulty with analogies, less often perseveration and imitation behaviour), and personality changes (mostly apathy and depression) was present in

Table 1 Characteristics of patients with PSP in three series confirmed by necropsy

\begin{tabular}{lccc}
\hline & Present series & Collins et al ${ }^{21}$ & De Bruin et al ${ }^{20}$ \\
\hline Sex & $9 \mathrm{~F} / 15 \mathrm{M}$ & $3 \mathrm{~F} / 9 \mathrm{M}$ & $34 \mathrm{~F} / 51 \mathrm{M}^{\star}$ \\
Age at onset (y) (mean (range)) & $63(45-73)$ & $66(48-77)$ & $62(47-78)$ \\
Disease duration (y) (mean (range)) & $6 \cdot 6(2-16 \cdot 6)$ & $5 \cdot 3(2-10)$ & $5(1-13)$ \\
Time to first visit (mean (SD)) & $3 \cdot 7(2)$ & $1 \cdot 5(0 \cdot 9)$ & NA \\
Time between visits (y) (mean (SD)) & $2 \cdot 2(1)$ & $\mathrm{NA}$ & NA \\
\hline
\end{tabular}

^Sex was not specified in five cases

No patients had history of encephalitis or familial disease; NA = data not available. 
Table 2 Features of patients with PSP in three series confirmed by necropsy

\begin{tabular}{|c|c|c|c|c|}
\hline Features & $\begin{array}{l}\text { Present series } \\
\text { first visit } \\
(n=24)(\%)\end{array}$ & $\begin{array}{l}\text { Present series } \\
\text { last visit } \\
(n=24)(\%)\end{array}$ & $\begin{array}{l}\text { Collins et al }{ }^{\prime \prime} \\
\text { last visit } \\
(n=12)(\%)\end{array}$ & $\begin{array}{l}\text { De Bruin et al } \\
\text { last visit } \\
(n=90)(\%)\end{array}$ \\
\hline \multicolumn{5}{|l|}{ Disease course: } \\
\hline Akinetic-rigid & $15(63)$ & $19(79)$ & NA & NA \\
\hline Mixed disease & $4(17)$ & $4(17)$ & NA & NA \\
\hline Tremor dominant & $1(4)$ & $1(4)$ & NA & NA \\
\hline \multicolumn{5}{|l|}{ Extrapyramidal features: } \\
\hline Gait disorders & $23(96)$ & $24(100)$ & NA & $63(71)$ \\
\hline Postural instability & $22^{\mathrm{a}}(92)$ & $24(100)$ & NA & $\mathrm{NA}$ \\
\hline Falls & $20(83)$ & $24(100)$ & $12(100)$ & $54(60)$ \\
\hline Falls in first year & $14(58)$ & - & $9(75)$ & NA \\
\hline Bilateral bradykinesia & $21^{\mathrm{a}}(88)$ & $23^{a}(96)$ & $11^{\mathrm{a}}(100)$ & $60(67)$ \\
\hline Axial rigidity & $15^{b}(63)$ & $20^{\mathrm{a}}(83)$ & NA & $52(58)$ \\
\hline \multicolumn{5}{|l|}{ Tremor, rigidity, or bradykinesia } \\
\hline (at least two) & $18(75)$ & $24(100)$ & $11^{\mathrm{a}}(100)$ & NA \\
\hline Tremor, rigidity, and bradykinesia & 3 (13) & $4^{\mathrm{a}}(17)$ & $2^{\mathrm{a}}(18)$ & NA \\
\hline Neck dystonia & $5^{a}(21)$ & $11(46)$ & $4(33)$ & $43(48)$ \\
\hline Rest tremor & $5(21)$ & $3(13)$ & $2^{\mathrm{a}}(18)$ & $15(17)$ \\
\hline Unilateral dystonia & $1(4)$ & $1(4)$ & $2^{\mathrm{a}}(18)$ & $18(20)$ \\
\hline \multirow{2}{*}{\multicolumn{5}{|c|}{$\begin{array}{l}\text { Treatment: } \\
\text { Levodopa }\end{array}$}} \\
\hline & & & & \\
\hline None or unknown & $12(52)$ & $9(35)$ & $3(25)$ & NA \\
\hline Pronounced response & $2(8)$ & $4(27)$ & $2^{\mathrm{a}}(18)$ & NA \\
\hline No response & $9(39)$ & $11(73)$ & $7(64)$ & NA \\
\hline \multicolumn{5}{|l|}{ Other features: } \\
\hline Supranuclear vertical palsy & $19(79)$ & $20^{\mathrm{a}}$ (19 downward) & 11 (10 downward) & $61(69)$ \\
\hline Dysarthria & $18^{\mathrm{b}}(75)$ & $24(100)$ & $11^{\mathrm{a}}(100)$ & $60(67)$ \\
\hline Frontal release signs & $13(54)$ & $19^{c}(79)$ & & NA \\
\hline Frontal lobe type symptomatology & $11^{\mathrm{d}}(46)$ & $4^{e}(58)$ & NA & NA \\
\hline Extensor plantar & $5(21)$ & $9(38)$ & $8^{\mathrm{a}}(66)$ & $30(34)$ \\
\hline Dysphagia & $4(16)$ & $20(83)$ & $6^{a}(55)$ & $51(58)$ \\
\hline Anomia & $1(4)$ & $4(17)$ & NA & NA \\
\hline
\end{tabular}

${ }^{2}$ Data missing in one patient; ${ }^{b}$ data missing in two patients; 'data missing in three patients; ${ }^{d}$ data missing in four patients; ${ }^{\text {edata }}$ missing in seven patients; NA = data not available.

11 of 20 patients. Dysphagia and neck dystonia were infrequent.

Details of treatment and initial response were known for 15 patients (table 2). Seventy three per cent of them did not benefit from levodopa treatment, and $27 \%(n=2)$ had a good response to levodopa ( $50-70 \%$ benefit), but the benefit lasted less than one year in one patient, and was unknown in another.

Fractures occurred in $25 \%$ of the patients, mostly early in the course of the disease (mean, 2.9 years after onset; range 0.5-6 years). Gait severity or falls during the first year of the disease were not correlated with the number of fractures.

Age at onset of symptoms was significantly correlated with the onset of falls during the first year of disease (Spearman $r=0.82 ; \mathrm{P}<$ $0 \cdot 0001)$. Patients who had recurrent falls during the first year of disease were significantly older $(67(1 \cdot 1)$ years) than those who did not (56.4 (1.3) years; ANOVA, $\mathrm{P}<0.0001)$. Patients with PSP who had begun falling during the first year of disease sought medical

Kaplan-Meier life table analysis of patients with PSP after onset of symptoms.

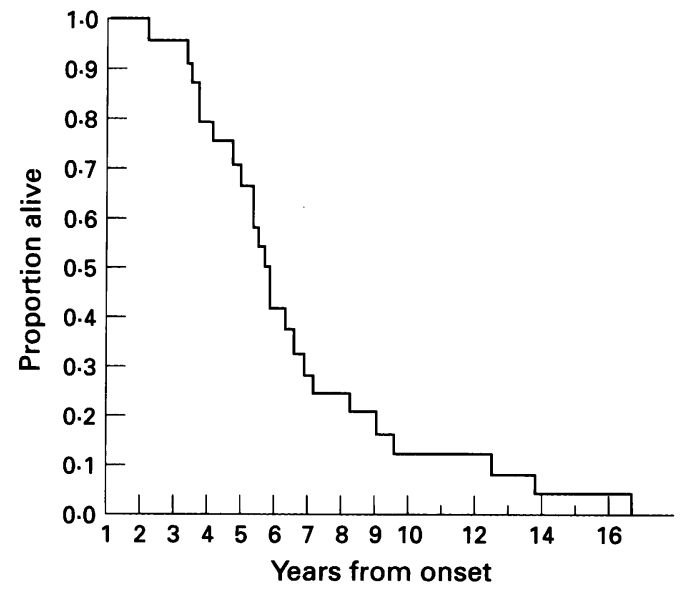

attention earlier (33.8 (7) months) than those who did not (59 (9) months; ANOVA, $\mathrm{P}<$ $0.04)$.

\section{SYMPTOMS AT LAST VISIT}

The last clinical visit occurred a mean of 5.9 (range, 1.6-16) years after onset of disease. In general, symptoms and signs that were apparent early in the course of PSP progressed steadily up to the last visit. The gait was abnormal with postural instability and bradykinesia in all of our patients (table 2); $67 \%(n=16)$ of the patients used a wheelchair. Axial rigidity was more common $(83 \%, n$ $=20)$ than retrocollis $(46 \%, n=11)$. Speech was always impaired: it was slurred $(n=22)$, dysphonic $(n=19)$, slow $(n=15)$, unintelligible $(n=10)$, palilalic $(n=3)$, mute $(n=3)$, echolalic $(n=2)$, ataxic $(n=2)$, or tachyphemic $(n=1)$. Few patients had what could be considered unusual motor features: one patient had unilateral dystonia, one myoclonus, three asymmetric parkinsonian signs, one motor neuron disease in the lower limbs, and one both tremor dominant disorder and resting tremor at onset of disease. A few patients had anomia, but aphasia or alien limb syndrome was never reported.

SURVIVAL

The median survival from onset of PSP was $5 \cdot 6(95 \%$ confidence interval $4 \cdot 8-7 \cdot 1$ years; figure), and after the first clinical visit it was 2.7 years. The onset of falls during the first year together with dysphagia and incontinence at the first visit predicted a shorter survival $\left(\chi^{2}\right.$ $=13.5, \mathrm{P}<0.003)$. The median survival of patients who had begun to fall during the first year of disease was shorter $(5 \cdot 2$ years) than those who did not $(6.8$ years; $P<0.05)$. Survival of two patients with PSP with early incontinence ( 3.2 and 3.3 years), and of one 
with early dystonia (two years) was brief. The only patient with tremor at onset and tremor dominant disease had the longest survival (16.6 years). Although patients with early dysphagia had a shorter survival (3.9 years) than those without ( 5.8 years), early dysphagia did not independently predict survival. Age at onset, sex, early onset of dementia, vertical supranuclear palsy, or axial rigidity had no effect on prognosis of survival.

CLINICAL DIAGNOSIS AND CAUSE OF DEATH The neurologists who clinically followed up these patients made a diagnosis of PSP in 58\% of the patients at the first visit (11 typical, three atypical); Parkinson's disease in $21 \%(\mathrm{n}=$ $5)$; corticobasal degeneration in $4 \%(n=1)$; multiple system atrophy in $4 \% \quad(n=1)$; Alzheimer's disease in $4 \%(n=1)$; and other disease in $8 \%(n=2)$. At the last visit, a diagnosis of PSP was made in $88 \%$ of the patients (14 typical, seven atypical). False negative misdiagnosis occurred with Parkinson's disease $(n=1)$, corticobasal degeneration $(n=$ $1)$, and other disorders $(n=1)$.

Thirteen of the 20 patients in whom the cause of death was known died of pneumonia (two with aspiration pneumonia), four of cardiovascular disorders (pulmonary emboli, myocardial infarct, congestive heart failure), and three of renal infections.

\section{LABORATORY TESTS}

Eighteen of the 24 patients had CT, MRI, or both. Eight patients had diffuse atrophy; one had atrophy of the tectum of the brainstem at a later stage; one had ventricular dilation compatible with normal pressure hydrocephalus; one had right temporal opercular infarct without a clinical history of stroke, which was not confirmed at necropsy; one had multiple foci of prolonged T2 in the white matter and putamen; and six were reported to be normal.

Six of the 24 patients had a single-photon emission computed tomography (SPECT). The iodoamphetamine SPECT showed varied results: one patient had bilateral frontal and basal ganglia hypoperfusion; one had bilateral orbitofrontal and left thalamic hypoperfusion; one had left basal ganglia, and left temporoparietal hypoperfusion; one had left parietooccipital and left frontal hypoperfusion; and one had right frontal, right basal ganglia and left cerebellum hypoperfusion; one scan was read as within normal limits. One patient had a PET with ${ }^{18}$ fluorodeoxyglucose, which showed bilateral frontal hypometabolism. Only one patient had a barium swallowing study, which showed difficulty initiating the swallow, lingual propulsion difficulties, delayed pharyngeal transit, and slow oral transit.

Fourteen patients with PSP had an EEG; 11 had diffuse, frontal or bitemporal slowing and three were normal.

\section{Discussion}

NATURAL HISTORY OF PSP

The patients with PSP usually presented in the seventh decade, and never before the age of
45 , with rapidly progressive postural instability and falls, followed by dysarthria and supranuclear vertical palsy, affecting either upward or downward gaze. Similar symptoms often occurred in other series confirmed by necropsy. ${ }^{19-22}$ Although falls often occur in elderly people secondary to various causes, ${ }^{25} 26$ the diagnosis of PSP should be considered when falls are associated with postural instability. Vertical supranuclear palsy, considered to be the hallmark of the disease, was present at disease onset in only a few patients. Much more commonly, vertical supranuclear palsy occurred several years after disease onset, or rarely, never developed, as previously reported. ${ }^{315222728}$ Downward gaze palsy is considered to be more specific for the diagnosis of PSP than is upward gaze palsy primarily because of age related restrictions in upward gaze. ${ }^{2930}$ In our patients, however, moderate to severe upward gaze palsy was more frequent than downward gaze abnormalities. Our findings suggest that downward gaze palsy might not be a requirement for the diagnosis of early PSP, and that upward gaze palsy in association with early gait instability and postural falls may be a better predictor of the disease.

Our patients with PSP also showed (as in other series; table 2) impaired behaviour consistent with frontal lobe dysfunction. In addition, they developed non-levodopa responsive parkinsonism that was typically manifested as a predominantly axial, symmetric akineticrigid syndrome, and occasionally with extensor neck dystonia. Despite its emphasis in the medical literature, ${ }^{29}$ neck dystonia was an infrequent early feature in our patients. Rest tremor and segmental dystonia were rarely seen, as in other series. ${ }^{21}$ A study ${ }^{22}$ which evaluated 16 pathologically confirmed PSP cases within three years of onset found that the symptoms progressed rapidly in $94 \%$; in $81 \%$ onset was symmetric; $50 \%$ had vertical supranuclear palsy; $56 \%$ had axial dystonia; and $50 \%$ cognitive impairment. Likewise, symptoms in our series progressed rapidly and steadily for an average of six years.

Although clinical series based on cases of PSP confirmed by necropsy may have more atypical cases, the demographics from our 24 patients with PSP confirmed by necropsy are similar to those of other clinicopathological and clinical series. ${ }^{15192231}$ The heterogeneity of patients with PSP is also increasingly recognised. ${ }^{15}$ Patients with PSP without ophthalmoplegia may have fewer falls and less axial dystonia, dysarthria, dysphagia, and rigidity. ${ }^{15}$ In our series, patients with PSP without early downward gaze palsy also had less axial rigidity. Interestingly, survival was longest in one of our three patients with PSP who never developed ophthalmoplegia and had other features suggestive of Parkinson's disease, such as asymmetric resting tremor at onset, tremor dominant disease, and late onset of dysarthria, dysphagia, and postural instability.

Differences in the occurrence of clinical features among the published series ${ }^{19}{ }^{20}$ may be partially explained by incomplete records. Even though we chose only records that were 
complete and participating centres are dedicated to the study of parkinsonian disorders, this is a retrospective study. Thus there may have been inconsistent recording of symptoms and signs. Moreover, there are always problems of reliability of recollection of data, particularly as the first visit occurred a mean of 3.7 years after the onset of symptoms. Patients may have not recalled the events and physicians may not have recorded patients' complaints or may not have probed them sufficiently. However, as these are tertiary centres, it is possible that patients would have come to their first visit with records from other primary centres. Only prospective population studies in which patient information is recorded in a standardised manner can provide us with the information for a definite natural history of PSP.

\section{MISDIAGNOSIS}

Errors in the diagnosis of our cases of PSP by the primary neurologists suggest that PSP is underdiagnosed-especially early in the course of the disease-as previously suggested. ${ }^{151632} 33$ The diagnosis of PSP is often confounded because several of its classic symptoms also occur in related disorders. For instance, supranuclear vertical gaze palsy occurs in other parkinsonian disorders, such as corticobasal degeneration, diffuse Lewy body disease, Creutzfeldt-Jakob disease, subcortical gliosis, or less commonly, multiple system atrophy. $1012162234-37$ In addition, supranuclear vertical palsy occurs in other treatable conditions, such as Whipple's disease ${ }^{38}$ or arteriosclerotic pseudoparkinsonism. In the early stages of the disease, PSP was most often confused with Parkinson's disease by the primary neurologists, whereas experienced neurologists (specialists in movement disorders) were most likely to confuse PSP with corticobasal degeneration. ${ }^{16}$

Features such as supranuclear vertical gaze palsy, rapid disease progression, early postural instability with falls, symmetric onset of akinetic-rigid parkinsonism that is unrelieved by levodopa, or pyramidal signs, help differentiate PSP from Parkinson's disease. ${ }^{39}$ Alien limb syndrome, severe asymmetric parkinsonism, cortical sensory deficits, severe ideomotor apraxia, myoclonus, or late onset of postural instability may help to differentiate corticobasal degeneration from PSP. ${ }^{36} 39$ 40 The confounding symptomatology points to the necessity of finding biological markers that will help make an earlier and definitive diagnosis of PSP.

\section{CLINICAL PREDICTORS OF SURVIVAL AND}

\section{MANAGEMENT ISSUES}

Onset of falls during the first year and early dysphagia and incontinence were useful predictors of shorter survival of patients with PSP. It is unclear whether these features indicate an unusually aggressive course of the disease or alternatively, promote secondary, life threatening complications. Other studies are also needed to determine whether tremor dominant disease could be a predictor of longer survival or whether early dystonia may shorten survival time.

Patients are not often questioned about symptoms suggestive of dysphagia (coughing or choking during meals) or silent aspiration (fever of an unknown origin), ${ }^{41} 42$ and barium swallowing studies are rarely requested, even though patients with PSP are often aware of their difficulty in swallowing. ${ }^{43}$ In our series, a barium swallow test was requested in only one patient, although the chance of detecting aspiration on clinical examinations is poor. ${ }^{44}$ Indeed, this is similar to what we find in our own clinical practices. Evaluation of patients with PSP by speech therapists specialising in swallowing disturbances may prevent complications such as silent aspiration pneumoniaprobably one of the most frequent causes of death in this disorder. Patients may benefit from changes in the consistency of the diet or from the low morbidity and mortality of current techniques such as percutaneous endoscopic gastrostomy.

The single highest cause of death in our patients with PSP was pneumonia, whereas it is ischaemic heart disease in normal controls and patients with Parkinson's disease. ${ }^{45}$ In our study, the cause of death cannot be explained by a certification artifact, ${ }^{46}$ because the events were recorded from findings at necropsy. Case-control studies with larger samples are needed to determine whether early management of dysphagia or other common complications prolong the survival of patients with PSP.

\section{LABORATORY TESTS}

The diagnosis of PSP was often not supported by MRI, principally because brainstem atrophy was not routinely evaluated, ${ }^{47-49}$ although the MRIs did exclude other diagnoses. The SPECT scans were not useful because they did not show the typical pattern of bilateral frontal hypometabolism disclosed by ${ }^{18}$ fluorodeoxyglucose PET. ${ }^{50-53}$ Although iodoamphetamine SPECT ${ }^{54}$ and imaging of dopamine D2 receptors with ${ }^{123}$ I-IBZM SPECT ${ }^{55}$ may be preferable, studies are needed to determine the role and cost effectiveness of SPECT in diagnosing PSP. An EEG was only helpful in excluding other rare disorders such as Creutzfeldt-Jakob disease.

In summary, better knowledge of the presenting symptoms, natural history of the disease, and features that predict survival will be helpful for making an earlier and more accurate diagnosis and prognosis of patients with PSP.

We thank Drs Jean-Jacques Hauw, Susan Daniel, Dennis Dickson, Dikran S Horoupian, Peter L Lantos, Kurt Jellinger, and Ann McKee for providing the cases for the NINDS database. We also thank Devera G Schoenberg for skilful editing.

1 Steele JC, Richardson JC, Olszewski J, Progressive supranuclear palsy. Arch Neurol 1964;10:333-59.

2 Duvoisin RC. Clinical diagnosis. In: Litvan I, Agid Y, eds Progressive supranuclear palsy: clinical and research approaches. New York: Oxford University Press, 1992 $15-33$

3 Nuwer M. Progressive supranuclear palsy despite normal eye movements. Arch Neurol 1981;38:784. 
4 Dubas F, Gray F, Escourolle R. Maladie de SteeleRichardson-Olszewski sans ophtalmoplegie. Rev Neurol 1983;139:407-16.

5 Masliah E, Hansen L, Quijada S, et al. Late onset dementia with argyrophilic grains and subcortical tangles or atypical progressive supranuclear palsy? Ann Neurol 1991;29: 389-96.

6 Matsuo $\mathrm{H}$, Takashima $\mathrm{H}$, Kishikawa $\mathrm{M}$, et al. Pure akinesia: an atypical manifestation of progressive supranuclea palsy. $\mathcal{F}$ Neurol Neurosurg Psychiatry 1991;54:397-400.

7 Mizusawa H. Pure akinesia and progressive supranuclear palsy. No To Shinkei 1993;45:113-8.

8 Dubinsky RM, Jankovic J. Progressive supranuclear palsy and a multi-infarct state. Neurology 1987;37:570-6.

9 Will RG, Lees AJ, Gibb W, Barnard RO. A case of progressive subcortical gliosis presenting clinically as SteeleRichardson-Olszewski syndrome. I Neurol Neurosurg Psychiatry 1988;51:1224-7.

10 Gibb WR, Luthert PJ, Marsden CD. Corticobasal degeneration. Brain 1989;112:1171-92.

11 Foster NL, Gilman S, Berent S, et al. Progressive subcortical gliosis and progressive supranuclear palsy can have similar clinical and PET abnormalities. $f$ Neuro Neurosurg Psychiatry 1992;55:707-13.

12 Jankovic J, Rajput AH, Golbe LI, Goodman JC. What is it? Case 1, 1993: parkinsonism, dysautonomia, and ophthalmoparesis. Mov Disord 1993;8:525-32.

13 Winikates J, Jankovic J. Vascular progressive supranuclear palsy. F Neural Transm Suppl 1994;42:189-201.

14 Revesz T, Daniel SE, Lees AJ, Will RG. A case of progressive subcortical gliosis associated with deposition of abnormal prion protein. I Neurol Neurosurg Psychiatry 1996;58:759-60.

15 Daniel SE, De Bruin VMS, Lees AJ. The clinical and pathological spectrum of Steele-Richardson-Olszewski pyndrome (progressive supranuclear palsy): a reappraisal. syndrome (progressive supr
Brain 1995;118:759-70.

16 Litvan I, Agid Y, Jankovic J, et al. Accuracy of clinical criteria for the diagnosis of progressive supranuclear palsy (Steele-Richardson-Olszewski syndrome). Neurology 1996 (in press)

17 Gearing M, Olson DA, Watts RL, Mirra SS. Progressive supranuclear palsy: neuropathologic and clinical heterogeneity. Neurology 1994;44:1015-24.

18 Hauw JJ, Daniel SE, Dickson D, et al. Preliminary NINDS neuropathologic criteria for Steele-Richardson-Olszewski syndrome (progressive supranuclear palsy). Neurology 1994;44:2015-9.

19 Brusa A, Mancardi GL, Bugiani O. Progressive supranuclear palsy 1979: an overview. Ital f Neurol Sci 1980;4: 205-22.

20 De Bruin VM, Lees AJ. Subcortical neurofibrillary degeneration presenting as Steele-Richardson-Olszewski and eration presenting as Steele-Richardson-Olszewski and other related syndromes: a review of 90

21 Collins SJ, Ahlskog JE, Parisi JE, Maraganore DM. Progressive supranuclear palsy: neuropathologically based diagnostic criteria. $f$ Neurol Neurosurg Psychiatry 1995;58:167-73.

22 Colosimo C, Albanese A, Hughes AJ, de Bruin VM, Lees AJ. Some specific clinical features differentiate multiple system atrophy (striatonigral variety) from Parkinson's disease. Arch Neurol 1995;52:294-8.

23 Litvan I, Hauw JJ, Bartko JJ, et al. Validity and reliability of the preliminary NINDS neuropathological criteria for progressive supranuclear palsy and rela

24 SAS Institute. $\mathcal{F M P}$ statistics for the Apple Macintosh. Cary, NC: SAS Institute Inc, 1994.

25 Tinetti ME, Speechley M. Prevention of falls among the elderly. N Engl ₹ Med 1989;320:1055-9.

26 Tinetti ME Inouye SK, Gill TM. Doucette JT. Shared risk factors for falls, incontinence, and functional dependence. Unifying the approach to geriatric syndromes. fAMA 1995;273:1348-53.

27 Pfaffenbach DD, Layton DDJ, Kearns TP. Ocular manifestations in progressive supranuclear palsy. $\mathrm{Am} f$ Ophthalmol 1972;74:1179-84.

28 Davis PH, Bergeron C, McLachlan DR. Atypical presentation of progressive supranuclear palsy. Ann Neurol 1985;17:

29 Lees AJ. The Steele-Richardson-Olszewski syndrome (progressive supranuclear palsy). Mov Disord 1987;2:272-87.

30 Troost B. Neuro-ophthalmological aspects. In: Litvan I, Agid Y, eds. Progressive supranuclear palsy: clinical and research approaches. New York: Oxford University Press,
1992:44-88.

31 Maher ER, Lees AJ. The clinical features and natural history of the Steele-Richardson-Olszewski syndrome (pro32 Golbe LI, Davis PH, Schoenberg BS, Duvoisin RC. Prevalence and natural history of progressive supranuclear palsy. Neurology 1988;38:1031-4

33 Golbe LI. Epidemiology. In: Litvan I, Agid Y, eds. Progressive supranuclear palsy: clinical and research approaches. New York: Oxford University Press, 1992: 33-43.

34 Fearnley JM, Revesz T, Brooks DJ, Frackowiak RS, Lees AJ. Diffuse Lewy body disease presenting with a supranuclear gaze palsy. F Neurol Neurosurg Psychiatry 1991;54:159-61.

35 De Bruin VM, Lees AJ, Daniel SE. Diffuse Lewy body disease presenting with supranuclear gaze palsy, parkinsonism, and dementia: a case report. Mov Disord 1992;7:355-8.

36 Rinne JO, Lee MS, Thompson PD, Marsden CD. Corticobasal degeneration. A clinical study of 36 cases. Brain 1994;117:1183-96.

37 Wenning G, Ben Shlomo Y, Magalhaes M, Daniel S, Quinn N. Clinical features and natural history of multiple system atrophy. An analysis of 100 cases. Brain 1994; 117:835-45.

38 Amarenco P, Roullet E, Hannoun L, Marteau R. Progressive supranuclear palsy as the sole manifestation of systemic Whipple's disease treated with pefloxacine [letter]. F Neurol Neurosurg Psychiatry 1991;54:1121-2.

39 Quinn N. Parkinsonism-recognition and differential diagnosis. BMF 1995;310:447-52.

40 Lang AE, Bergeron C, Pollanen MS, Ashby P. Parietal Pick's disease mimicking cortical-basal ganglionic degeneration. Neurology 1994;44:1436-40.

41 Feinberg MJ, Knebl J, Tully J, Segall L. Aspiration and the elderly. Dysphagia 1990;5:61-71.

42 Longemann IA. Evaluation and treatment of swallowing disorders. San Diego: College-Hill Press, 1983.

43 Sonies BC. Swallowing and speech disturbances. In: Litvan I, Agid Y, eds. Progressive supranuclear palsy: clinical and research approaches. New York: Oxford University Press, 1992:240-53.

44 Splaingard ML, Hutchins B, Sulton LD, Chaudhuri G. Aspiration in rehabilitation patients: videofluoroscopy vs bedside clinical assessment. Arch Phys Med Rehab 1988; 69:637-40.

45 Ben-Shlomo Y, Marmot MG. Survival and cause of death in a cohort of patients with parkinsonism: possible clues to aetiology? F Neurol Neurosurg Psychiatry 1995;58:293-9.

46 Kircher T, Nelson J, Burdo $H$ The autopsy as a measure of accuracy of the death certificate. $N$ Engl $f$ Med 1985; 313:1263.

47 Schonfeld SM, Golbe LI, Sage JI, Safer JN, Duvoisin RC. Computed tomographic findings in progressive supranuclear palsy: corr

48 Savoiardo M, Strada L, Girotti F, et al. MR imaging in progressive supranuclear palsy and Shy-Drager syndrome. $\mathcal{F}$ Comput Assist Tomogr 1989;13:555-60.

49 Savoiardo M, Girotti F, Strada L, Ciceri E. Magnetic resonance imaging in progressive supranuclear palsy and other parkinsonian disorders. $f$ Neural Transm Suppl 1994;42:93-110

50 Burn DJ, Sawle GV, Brooks DJ. Differential diagnosis of Parkinson's disease, multiple system atrophy, and SteeleRichardson-Olszewski syndrome: discriminant analysis of striatal ${ }^{18}$ F-dopa PET data. $\mathcal{F}$ Neurol Neurosurg Psychiatry 1994;57:278-84.

51 Brooks DJ. PET studies in progressive supranuclear palsy. $\mathcal{f}$ Neural Transm Suppl 1994;42:119-34.

52 Blin J, Horwitz B, Baron J, Agid Y. Does frontal cortex hypometabolism in progressive supranuclear palsy result 221-8.

53 Foster NL, Gilman S, Berent S, et al. Progressive subcortical gliosis and progressive supranuclear palsy can have similar clinical and PET abnormalities. $f$ Neurol Neurosurg Psychiatry 1992;55:707-13.

54 Ghika J, Tennis M, Growdon J, Hoffman E, Johnson K. Environment-driven responses in progressive supranuclear palsy. F Neurol Sci 1995;130:104-11.

55 VanRoyen E, Verhoeff NF, Speelman JD, Woletrs EC Kuiper MA, Janssen AG. Multiple system atrophy and progressive supranuclear palsy. Diminished striatal D2 dopamine receptor activity demonstrated by ${ }^{123}$ I-IBZM single-photon emission computed tomography. Arch Neurol 1993;50:513-6. 